\title{
Male Body-image Self-consciousness during Physical Intimacy (M-BISC): Validating the M-BISC with Gay Men
}

\begin{tabular}{|c|c|}
\hline Journal: & Journal of Sexual Medicine \\
\hline Manuscript ID & JSM-03-2018-145.R2 \\
\hline Article type: & Original Research \\
\hline Keywords: & $\begin{array}{l}\text { body consciousness, gay men, intimacy, body image, psychometrics, } \\
\text { validation }\end{array}$ \\
\hline Subject Area: & LGB sexuality, Male sexual desire disorders \\
\hline Abstract: & $\begin{array}{l}\text { Abstract } \\
\text { Introduction: An expanding area of research within the realm of body } \\
\text { image is its role in human sexual functioning, which denotes people's } \\
\text { overall satisfaction with their performance during a specific sexual } \\
\text { encounter. Traditionally, studies investigating the association between } \\
\text { body image and sexual functioning have focused on women. The Male } \\
\text { Body-Image Self-consciousness Scale (M-BISC) was developed to } \\
\text { exclusively assess male body-image self-consciousness during sexual } \\
\text { activity using a sample consisting primarily of heterosexual men. } \\
\text { Aim: The purpose of the current study is to evaluate the dimensionality, } \\
\text { reliability and validity of the M-BISC with a sample of gay men. Research } \\
\text { suggests that sexual difficulties (SD) and body image concerns can } \\
\text { overlap and interrelate. Therefore, two subscales (ED: Erectile Difficulties } \\
\text { and BE: Body Embarrassment) from the Gay Male Sexual Difficulties } \\
\text { Scale (GMSDS) were used to assess the validity of the scale. } \\
\text { Method: Nine-hundred and thirty men self-identifying as "exclusively } \\
\text { gay" completed an online survey consisting of demographics, the M-BISC } \\
\text { and GMSDS (ED and BE subscales). } \\
\text { Main Outcome Measures: The replicability of the M-BISC factor structure } \\
\text { with a gay male sample was determined using an exploratory and } \\
\text { confirmatory factor analysis. Additionally, the GMSDS (ED and BE } \\
\text { subscales) was used to determine the validity of the MBISC. } \\
\text { Results: Exploratory and confirmatory factor analyses revealed that, } \\
\text { following the removal of three items, the M-BISC was unidimensional. } \\
\text { Scale score reliability for the } 14-i t e m \text { M-BISC was good. Finally, as } \\
\text { predicted, scores on the M-BISC correlated with scores on the GMSDS } \\
\text { (i.e., greater sexual difficulties). } \\
\text { Conclusion: Results of the current study illustrate that the M-BISC is a } \\
\text { valid tool to measure gay men's body concerns during intimacy. More } \\
\text { importantly, it also highlights gay men elevated body concerns during } \\
\text { intimacy and the need to understand the aetiology of these } \\
\text { apprehensions. Currently, there is a noticeable gap in the literature } \\
\text { regarding the cause of gay male body concerns that have potential clinic } \\
\text { implications. }\end{array}$ \\
\hline
\end{tabular}




\section{SCHOLARONE ${ }^{\text {TM }}$ \\ Manuscripts}


RUNNING HEAD: VALIDATING THE M-BISC WITH GAY MEN

\begin{abstract}
Introduction: An expanding area of research within the realm of body image is its role in human sexual functioning, which denotes people's overall satisfaction with their performance during a specific sexual encounter. Traditionally, studies investigating the association between body image and sexual functioning have focused on women. The Male Body-Image Selfconsciousness Scale (M-BISC) was developed to exclusively assess male body-image selfconsciousness during sexual activity using a sample consisting primarily of heterosexual men.
\end{abstract}

Aim: The purpose of the current study is to evaluate the dimensionality, reliability and validity of the M-BISC with a sample of gay men. Research suggests that sexual difficulties (SD) and body image concerns can overlap and interrelate. Therefore, two subscales (ED: Erectile Difficulties and BE: Body Embarrassment) from the Gay Male Sexual Difficulties Scale (GMSDS) were used to assess the validity of the scale.

Method: Nine-hundred and thirty men self-identifying as "exclusively gay" completed an online survey consisting of demographics, the M-BISC and GMSDS (ED and BE subscales).

Main Outcome Measures: The replicability of the M-BISC factor structure with a gay male sample was determined using an exploratory and confirmatory factor analysis. Additionally, the GMSDS (ED and BE subscales) was used to determine the validity of the MBISC.

Results: Exploratory and confirmatory factor analyses revealed that, following the removal of three items, the M-BISC was unidimensional. Scale score reliability for the 14-item M-BISC was 
good. Finally, as predicted, scores on the M-BISC correlated with scores on the GMSDS (i.e., greater sexual difficulties).

Conclusion: Results of the current study illustrate that the M-BISC is a valid tool to measure gay men's body concerns during intimacy. More importantly, it also highlights gay men elevated body concerns during intimacy and the need to understand the aetiology of these apprehensions. Currently, there is a noticeable gap in the literature regarding the cause of gay male body concerns that have potential clinic implications. 
Body image is a multidimensional phenomenon comprised of self-perceptions and attitudes towards one's physical appearance[1]. The two key facets of body image are: (1) individuals' evaluative thoughts about their physiques; and (2) the degree to which individuals are invested in how they look[1]. An expanding area of research within the realm of body image is its role in human sexual functioning, which denotes people's overall satisfaction with their performance during a specific sexual encounter[2][3].

Traditionally, studies investigating the association between body image and sexual functioning have focused on women[4]. Furthermore, certain scales that were created to measure men's body image concerns in relation to sexual difficulties (SD) ${ }^{1}$ are based on instruments designed for women (e.g., Cognitive Distraction and Women's Sexual Functioning scale)[4][5]. A small number of studies have measured the construct using scales that were validated for use with men. To illustrate: an investigation of the psychometric properties of the Body Exposure during Sexual Activities Questionnaire (BESAQ)[6] found that body mass index correlated positively with anxious self-focus and exposure avoidance during intimacy. Furthermore, men's scores on the BESAQ were positively associated with being concerned about weight and appearance investment, and negatively correlated with self-reported sexual desire, arousal, and orgasm experience.

Although the BESAQ filled a notable gap in the study of body image and sexual functioning, it has limitations when used with men - gay or straight. First, the language contained in the measure is not gendered; thus, none of the scale items employ terminology that particularizes men's unique body concerns. For example, according to research, men worry about the length and circumference of their penis[7][8][9]; however, the BESAQ does not reference men's genitals. Second, the extent to which men were used to develop BESAQ items is 
unclear[4]. If male participants were omitted from the generation and refinement of scale items then it is difficult to gauge whether the BESAQ is a content valid measure of male body image and sexual functioning.

\section{Male Body-Image Self-consciousness Scale (M-BISC)}

To address the potential limitations of the BESAQ, McDonagh et al. created the Male Body-Image Self-consciousness Scale (M-BISC)[4]. The M-BISC was developed to exclusively assess male body-image self-consciousness during sexual activity. The M-BISC items were generated in consultation with a small group of men ( 3 students in the final year of their undergraduate degree at a Republic of Ireland university). The following protocol was adopted. Copies of a scale designed to measure female body image self-consciousness during physical intimacy[2] were distributed to the group and discussed, with each item assessed individually with regards to whether or not it was pertinent to men. This discussion led to the creation of a 39item measure which then was subject to pilot-testing. One hundred and thirty-six men residing in the Republic of Ireland completed a questionnaire packet consisting of the Body Esteem Scale[10], the Drive for Muscularity Attitudes Questionnaire (DMAQ)[11], the Sexual Anxiety Inventory[12] and the Sexual Esteem Scale (SES)[13]. Body weight, relationship status, sexual experience and self-rated bodily attractiveness also were evaluated.

For the M-BISC, corrected item-total correlations were inspected and 5 items that had correlation coefficients less than .30 were deleted. After recalculating corrected item-total correlations, two items correlated with each other in excess of .70. To minimize redundancy, the item with the lowest variance was removed. Sixteen items also were deleted because their interitem correlations were weak $(<.30)$. Thus, 17 items, in total, were retained. Cronbach's alpha for the 17-item M-BISC was .92, which suggests good scale score reliability. 
To test the M-BISC's construct validity, the researchers generated five hypotheses, all of which were supported. As predicted: 1) Men's body dissatisfaction correlated with their body image self-consciousness during sexual intimacy (BES and M-BISC); 2) Men's sexual esteem correlated negatively with self-consciousness (SES and M-BISC); 3) Men's levels of sexual anxiety and self-consciousness correlated moderately (SAI and M-BISC); 4) Men's self-rated physical attractiveness was negatively related to self-consciousness (self-rated physical attractiveness and M-BISC); and 5) Men's drive for muscularity correlated positively with their self-consciousness (DMAQ and M-BISC). For additional details about the development and validation of the M-BISC see McDonagh et al.[4].

Although the creation of the M-BISC has provided researchers with an opportunity to measure male body image concerns during sexual activity, the scale was validated with a predominately heterosexual sample (i.e., over $90 \%$ of the participants reported that they were "exclusively heterosexual" or "more heterosexual than homosexual")[4]. Studies targeting nonheterosexual respondents are warranted because previous research suggests that gay and heterosexual men have differing attitudes on body image ${ }^{2}$. Generally, gay men have significantly lower body satisfaction and higher occurrences of eating disorders than do heterosexual $\operatorname{men}[14][15][16][17]$. Studies also have observed that gay men score significantly higher than heterosexual men on measures of the drive for muscularity, and that their positive self-appraisals are highly dependent on appearance, weight, and muscularity[18][14][19][20]. Thus, distributing the M-BISC to gay male samples may permit researchers to better understand gay men's body image during physical intimacy and the role such perceptions may (potentially) play in SD.

\section{Gay Men's Body Image and Sexual Difficulties}


Comparable to research pertaining to the broad concept of body image, literature evaluating the potential relationship between SD and appearance disproportionately focuses on heterosexual women[21]. Furthermore, the few studies assessing body image and SD in men choose to isolate men's genital concerns in relation to sexual functioning (i.e., penis length and girth, circumcision status)[22][23] rather than explore the entirety of the male body. This field of research tends to prioritize heterosexual men's body concerns during intimacy and (often) include a small, incidental sample of gay men or collapse men's sexual preferences into a single group. However, the scant literature available suggests that there is an observable relationship between body image concerns and SD in gay men.

In a study evaluating heterosexual men and women, gay men, and lesbian women's body image satisfaction and its association with their sexual lives, $42 \%$ of the gay male participants reported that their negative body image had a detrimental effect on the quality of their sex life (in comparison to $22 \%$ of the heterosexual male participants)[24]. Lacefield and Negy observed that sexual minorities experience significantly more non-erotic cognitive distractions during sexual activity than do heterosexual men and women[22]. Non-erotic cognitive distractions refer to physical performance distractions (e.g., anxiety about partner's sexual experience), body image concerns, and other cognitive distractions (e.g., STI and emotional concerns) during sexual activity. Moreover, gay men experienced the most body image concern during intimacy when compared to lesbian women and heterosexual men and women. Lastly, in a comparative study assessing SD in a sample of heterosexual and gay Croatian men, positive body image was inversely associated with self-reported SD for gay male participants, but not for heterosexual men[25]. Although the amount of research pertaining to gay men's SD and body image concerns is relatively small, the existing literature implies the two variables may be correlated. 
Specifically, higher levels of body self-consciousness may be associated with the occurrence of a wide range of SD in gay men.

\section{Purpose}

Previously, the psychometric robustness of the M-BISC has been tested with a sample composed of heterosexual men[4]. Literature suggests that assessing gay men's sexual attitudes and behaviours with measures that have been validated with heterosexual men can be problematic[26]. In addition, since the development of the M-BISC, research has yet to be published that analyzes the dimensionality, reliability, and validity of the M-BISC among gay men. ${ }^{3}$ Thus, the purpose of the current study is to evaluate the basic psychometric features of the M-BISC using a large sample of gay men.

\section{Method}

\section{Participants}

Nine-hundred and thirty men self-identifying as "exclusively gay" served as participants. They ranged in age from 18 to $76(M=33.55, S D=11.23)$. Most participants were Caucasian $(n$ $=795 ; 85.5 \%)$, and currently resided in the United States $(n=418 ; 44.9 \%)$, Ireland $(n=140$; $15.1 \%)$, the United Kingdom $(n=116 ; 12.5 \%)$, and Canada $(n=64 ; 6.9 \%)$. In addition, a majority of participants were either employed full-time $(n=573 ; 61.6 \%)$ or enrolled in postsecondary school $(n=192 ; 20.6 \%)$. Finally, with respect to participants' relationship status, $34.6 \%(n=322)$ stated that they were single (not dating); $17.8 \%(n=166)$ indicated that they were dating one person exclusively; $15.9 \%(n=148)$ were living with their partner; and 10.3\% $(n=96)$ were married or in a civil partnership.

\section{Procedure}


Ethical approval was obtained from the research ethics committee affiliated with the third author's university. Using Surveygizmo®, a questionnaire pack was created which consisted of an information sheet, informed consent and relevant measures. The participant information sheet, presented on the first page of the survey, clearly stated that only men aged 18 years and older were eligible to participate. The purpose of the study and ethical requirements for research with human participants were described (i.e., participation was anonymous and voluntary). The consent sheet appeared under the information sheet; demographic questions and all scales were presented on the remaining pages. Secure Sockets Layer encryption was used to ensure participant confidentiality.

Participants were recruited through a variety of means. In Ireland, a national campaign was launched seeking participation from all gay men aged 18 years and over. Advertisements were placed in local and national newspapers, and the research was discussed on local and national radio stations. Posters detailing the study were displayed in gay bars and nightclubs throughout Ireland. Internationally, LGBT organisations and groups (e.g., Pride event organisers) were contacted and asked to forward "an invitation e-mail" to their members. Invitations to participate in a study on SD were posted online in several locations (e.g., blogs, websites, and discussion forums). The administrators of these websites, blogs and forums were also asked to forward information about the study to personal contacts. As well, chain-referral sampling was used whereby acquaintances of the authors were asked to inform other men about the study. A Facebook page (“Gay Men's Sex Survey”) was created, which described the research and provided links to the survey. Other LGBT-related Facebook pages (e.g., gay choirs) also were contacted and asked to post a link to the survey on their page.

\section{Measures}


In addition to demographic questions (e.g., age, sexual orientation, and ethnicity), participants were required to complete:

Male Body Image Self-Consciousness (M-BISC)[4][27]. The M-BISC is a 17-item measure of male body self-consciousness during sexual activity. Each question is answered using a five-point Likert scale ( 1 = strongly disagree; 5 = strongly agree), with total scores ranging from 17 to 85 (higher scores denote greater body image self-consciousness). McDonagh et al. provided evidence attesting to the scale score validity and reliability of the measure when distributed to heterosexual men.

Gay Male Sexual Difficulties Scale (GMSDS)[28]. The 25-item GMSDS utilizes a Likerttype response format (Not Applicable, Never, Once or Twice, Several Times, Most of the Time, All of the Time), and examines: difficulties with receptive and insertive anal intercourse (5 items each, 1 = strongly disagree; 5 = strongly agree); erectile difficulties (4 items, $1=$ strongly disagree; 5 = strongly agree); foreskin difficulties ( 4 items, $1=$ strongly disagree; $5=$ strongly agree); body embarrassment (4 items, 1 = strongly disagree; $5=$ strongly agree); and seminal fluid concerns ( 3 items, 1 = strongly disagree; 5 = strongly agree). For all subscales, higher scores denote more frequent occurrence of the SD in question. McDonagh et al. provide evidence suggesting that the GMSDS possesses good psychometric properties. In the current study, the erectile difficulties (ED) and body embarrassment (BE) subscales were used to furnish strands of evidence in support of the construct validity of the M-BISC. In the current study the reliability for the subscales was excellent $(\mathrm{ED}: \Theta=.90 ; \mathrm{BE}: \Theta=.89)$

\section{Data Analytic Plan}

The sample was randomly divided into two subsamples (henceforth called Sample A $[n=$ 459] and Sample B [ $n=471])$. First, to determine if the items loaded similarly for gay men, in 
comparison to McDonagh et al.[4], an exploratory factor analysis (EFA) was conducted using Sample A. Following this, the results of that analysis were then tested via confirmatory factor analysis (CFA) with Sample B. Scale score reliability and indicators of construct validity (specifically, convergent validation) were tested separately for each sample.

\section{Results}

Sample A: Dimensionality. The M-BISC uses a Likert-type response format and, thus, should be conceptualized as providing ordinal rather than interval data. Unfortunately, in most commonly used statistical packages (e.g., SPSS), exploratory factor analyses cannot be conducted using polychoric correlations, which are appropriate when data are ordinal. To address this limitation, R programming language was employed via an SPSS plug-in (see Basto and Pereira[29]).

The dimensionality of the M-BISC was examined using principal axis factor analysis (PAF), with oblique rotation (direct oblimin). To assist with factor retention, parallel analysis was utilized. This method has been identified as one of the most accurate in identifying the appropriate number of factors to retain (i.e., unlike other retention techniques such as the eigenvalue greater than 1 "rule," parallel analysis seldom over- or under-extracts[30].

A host of diagnostic tests revealed that the data were suitable for EFA. Specifically, the Kaiser-Meyer-Olkin's measure of sampling adequacy was .92; the determinant was .0001; and Bartlett's test of sphericity was statistically significant $\left(\chi^{2}=5378.392, p<.0001\right)$. Inspection of individual measures of sampling adequacy (IMSAs) similarly revealed good values $(.80+)$ for all items, with the exception of "I would have difficulty taking a shower or a bath with a partner," which was slightly below the .80 cut-off (i.e., .784). 
The first eigenvalue generated by the real dataset was 8.50 , which exceeded the eigenvalue created by the randomly created polychoric correlation matrices (1.41). The second eigenvalue for the real dataset was 1.53 , which was negligibly greater than the eigenvalue associated with the random correlation matrices (1.33). The proportions of variance accounted for by these factors were $49.97 \%$ and $9.00 \%$. Thus, based on the parallel analysis, one-factor or two-factor solutions seem viable.

To determine whether the second factor possessed incremental value, the unrotated factor matrix was inspected. Only one item loaded uniquely on Factor 2 (I would have difficulty taking a shower or a bath with a partner [.466]). However, as single item factors are inadvisable, it was decided that a one-factor solution should be retained.

A one-factor solution was then forced. Three of the 17 items had loadings less than the .40 minimum recommended and, thus, were removed[31]. Factor loadings for the remaining 14 items are provided in Table 1. Inspection of this table reveals that the retained items had loadings ranging from .44 to .87 .

Sample B: Dimensionality. The replicability of the one-factor solution obtained with Sample A was tested with Sample B using confirmatory factor analysis (CFA). AMOS version 22.0 was utilized. Model fit was assessed using multiple criteria: 1) Root Mean Square Error of Approximation (RMSEA); 2) Bentler's comparative fit index (CFI); and 3) the Tucker-Lewis fit Index (TLI). Stringent thresholds were utilized: RMSEA $<.08$, CFI $>.90$, TLI $>0.90$ indicate adequate fit while RMSEA $<.06$, CFI $>.95$, and TLI $>.95$ denote excellent fit[32]. It is important to note that, while chi-square is often used to gauge fit, evidence suggests that statistical significance (i.e., inadequate model fit) may be due to a large sample size (Kline, 2011). The initial CFA suggested that a unidimensional model for the 14-item M-BISC was 
unacceptable: $\mathrm{RMSEA}<.100, \mathrm{CFI}=0.85, \mathrm{TLI}=0.89$. Thus, to achieve acceptable model fit, four covariances were introduced (see Table 2) and the resulting model suggested satisfactory fit: $\mathrm{RMSEA}=.078, \mathrm{CFI}=.94 ; \mathrm{TLI}=.94$. Factor loadings ranged from .53 to .79 (see Table 3$)$.

Samples A and B: Scale Score Reliability. For scale score reliability, the most commonly utilized estimate is Cronbach's alpha, which is the expected correlation between an actual test and a hypothetical alternative form of the same length[33]. However, Cronbach's alpha has been subject to substantial criticism because it uses a tau-equivalent model which operates in accordance with a specific set of assumptions; ones that are rarely met in psychological data (see Peters, 2004). Thus, other forms of scale score reliability have been recommended in lieu of Cronbach's alpha, such as Theta. Ordinal Theta is often used to determine the scale score reliability of ordinal data, which the M-BISC produces[34]. The ordinal theta scores for the current measure were excellent (Sample A, $\Theta=.95$, Sample B, $\Theta=$ 95.)

Samples A and B: Rates of Endorsement on the M-BISC. Eight of the 14 items on the M-BISC had endorsement rates in excess of $25 \%$ (see Table 4). Specifically, over half of the participants from both samples reported they would be "worried that [their] partner would get turned off by seeing [their] body without clothes"; "concerned about how [their] body looks to a partner"; and "worried that [their] partner would think [their] stomach is not muscular enough." Sizeable proportions (i.e., $35 \%$ to $45 \%$ ) also endorsed items measuring concerns about insufficient muscularity, being perceived as unattractive to a partner, and being regarded as "too fat" when engaging in "sexually intimate situations." The two items that evidenced the lowest rates of endorsement (i.e., $<10 \%$ ) were: 1) embarrassment about the size of one's testicles and 2) experiencing anxiety when contemplating "having sex without any covers over [one's] body." 
Samples A and B: Convergent Validity. To provide additional strands of evidence in support of the scale score validity of the 14-item M-BISC, total scores for that scale were correlated with total scores on the erectile difficulties (ED) and body embarrassment (BE) subscales of the GMSDS. As research suggests that SD (including but not limited to ED) and body self-consciousness are frequently related[35], it was predicted that gay men's experiences with erectile difficulties and body embarrassment would correlate positively with their bodyimage self-consciousness during physical intimacy. Support for these two predictions would provide one strand of evidence attesting to the construct validity of the M-BISC when completed by gay men. As predicted, participants' level of body self-consciousness during physical intimacy correlated significantly with scores on the ED and BE: Sample A (erectile difficulties: $r$ $[457]=.10, p<.001 ;$ body embarrassment: $r[436]=.57, p<.001)$ and Sample B (erectile difficulties: $r$ [469] $=.10, p<.001$; body embarrassment, $r[451]=.51, p<.001)$. It should be noted that, while statistically significant, the correlations observed between the M-BISC and the ED were weak.

\section{Discussion}

The purpose of the current study was to determine whether the M-BISC was a reliable and valid measure of gay men's body image concern during sexual intimacy. Previously, the psychometric properties of the measure had been tested with a sample that largely consisted of heterosexual men. Research has indicated that assuming measures only validated with heterosexual persons are suitable for use with sexual minorities is problematic and may lead to inaccurate results[28]. Operating from this perspective, we conducted the current study to explicitly test the psychometric properties of the M-BISC when completed by a large number of self-identifying gay men. 
We were able to replicate the unidimensional factor structure of the M-BISC noted by McDonagh et al.[4]. However, doing so required the deletion of three items. The unidimensionality of this measure was corroborated using confirmatory factor analysis (CFA); a statistical procedure which, to date, has not been conducted with M-BISC data.

A subsidiary goal was to explore the relationship between men's body image concerns during intimacy and SD[19][20]. We utilized McDonagh and associates' GMSDS (ED and BE subscales specifically)[28] to explore the construct validity of the M-BISC. A strong correlation was observed between the M-BISC and the BE thereby attesting to the former's construct validity. Unfortunately, while statistically significant, the correlation between the M-BISC and ED was of little practical importance ( $r \mathrm{~s}=.10$ and .10 for Samples A and B, respectively). Although previous research suggests that SD and body image dissatisfaction are related (i.e., more body image concerns predict higher $\mathrm{SD}[6]$ ), it is important to note that much of this work involves general questions about overall sexual satisfaction and does not particularize specific $\mathrm{SD}[21][24]$. Findings from our study suggest that, for gay men, certain types of SD (e.g., body embarrassment) may be more strongly associated with self-consciousness during physical intimacy than other types (e.g., erectile difficulties). However, further research is needed to determine the replicability of these results.

According to the frequencies computed (see Table 4), a large proportion of the participants in the current study appear to be dissatisfied with their bodies (e.g., leanness, lack of muscularity). These findings are consistent with previous research assessing gay men's body image satisfaction. For example, in studies evaluating eating behaviours, attitudes towards exercise and body image in men, gay men were more likely than heterosexual men to evidence distorted cognitions regarding the importance of obtaining and maintaining an ideal 
physique[15][19] Also, research has found that gay men were dissatisfied with their level of muscularity[16][35]or reported feeling "pressure" to be more muscular[35][36] The factors that contribute to gay men's apparent dissatisfaction with their muscularity are unclear, although gay male cultural products in the form of pornography and lifestyle media may play a role $[37][38][39]$.

Three items were removed from the M-BISC because they had relatively weak factor loadings (i.e., less than .40). These items were: I would worry about the length of my erect penis during physically intimate situations; I would have difficulty taking a shower or a bath with a partner; and If a partner were to see me nude, I would be concerned about the overall muscularity of my body. With respect to the first item, it has been noted that gay men are often concerned about the length and circumference of their penis[7][8]; thus, it may seem peculiar that this statement did not appear to be salient to our sample of gay men. However, Simpson and Adams' recent systemic review of previous research $(N=26)$ pertaining to the genital perceptions of heterosexual men and men who have sex with men (MSM; includes gay men) suggests that penis size may not be a source of body dissatisfaction for MSM[9]. Simpson and Adams found that a greater portion of MSM considered their penis "above average" (35\%) compared to heterosexual men $(22 \%)$ whereas a smaller proportion of MSM deemed their penis to be "below average" in length (6\% versus $12 \%$ for straight men)[9]. The second item that did not load involved nudity in the shower or bath. A bath or shower may precede sexual acts, and therefore, a certain level of familiarity has been realized during the initial sexual encounter that serves to reduce body shame. The long and the short of it: the sexual partners may have already seen each other nude prior to bathing. In assessing "overall muscularity," the final item might be too general for gay men and, thus, better reflected in the more specific statements that pertain to muscularity of the 
chest and stomach. Thus, it may suggest that gay men's body image concerns may arise from a lack of muscularity for certain body parts or areas, rather than their entire body.

The current study was not without limitations. First, the M-BISC was developed primarily with a small group of heterosexual men and then validated with a sample consisting of $10 \%$ gay men[4]. Therefore, by attempting to validate the M-BISC with a sample of gay men the following study accepts that heterosexual men's body concerns are shared by their gay counterparts. It might be worthwhile piloting the 14-item M-BISC with a small sample of gay men to determine if they deem its content sufficiently representative of their corporeal concerns with interacting sexually with another man. If gaps are identified, then additional items should be generated and added to the revised M-BISC. Doing so, would underscore the iterative nature of psychometric testing (i.e., measures continually need to refined and improved). Second, due to the sexual nature of the research, our participants might have been more open to discussing sexual topics and expressing sexual concerns (i.e., in general, more erotophillic). Erotophilia refers to a person who is open to his/her sexuality and generally has more sex-positive attitudes[40][41]. Third, although online surveys can be advantageous for measuring sexual function due to participant anonymity and can be representative of a non-Internet sample[42][43], the format also has limitations. For instance, the completion criteria of the study could not be monitored as is possible within a more structured setting. The researchers also could not provide feedback or assistance while participants completed the survey. As well, individuals without computers or Internet access could not be recruited[42]. We recommend that future studies attempt to replicate our findings using more traditional methods of data collection (i.e., pen and paper). 
The current study attempted to access a wide range of ethnicities and cultures by targeting a worldwide community sample; however, the majority of participants were Caucasian and originated from Western countries. Consequently, it is unknown whether the M-BISC is a valid tool to measure body image concerns during intimacy with gay men of all ethnicities and cultural backgrounds. The current study used a measure of SD to validate the M-BISC and, within this realm of research, differences have been noted between men of different ethnic and cultural backgrounds. For instance, Laumann et al. reported that Black individuals were more likely and Hispanic persons less likely to experience SD[44][45]. Therefore, future studies should attempt to capture a more ethnically diverse sample.

Lastly, the current study utilized a correlational and cross-sectional design to investigate the relationship between the variables of interest. The potential causes and effects of gay men's SD and body image concerns during intimacy cannot be separated. For example, one cannot conclude that SD lead to poor levels of body image during intimacy; this relationship may be reversed or reciprocal.

\section{Conclusion}

The results of the current study suggest that the M-BISC is a valid tool to measure gay men's body concerns during intimacy. More importantly, it also highlights gay men's elevated body concerns during physical intimacy, especially in terms of being "insufficiently" muscular and the need to understand the aetiology of these apprehensions. Currently, there is a noticeable gap in the literature regarding the cause of gay male body concerns that have potential clinical implications. 


\section{Notes}

1. The non-clinical label, "sexual difficulties (SD)," refers to any disturbance in normal sexual responding that can negatively affect men's social and psychological well-being and quality of life regardless of timeframe[29][46][47][48].

2. Not all measures have been purposely developed without gay participants. Instead, there may have been an availability issue whereby few gay participants were available.

3. Loehle et al. assessed predictors of genital-self esteem across geographic regions in men who has sex with men (MSM) and heterosexual men using the M-BISC[48]. However, the researchers considered the scale to be a general indicant of body image for men, rather than body consciousness during intimacy. The researchers also did not provide separate correlation or regression models for heterosexual versus gay men so the presence or absence of difference between the two groups on predictors cannot be determined. 


\section{Acknowledgements}

This research did not receive any specific grant from funding agencies in the public, commercial, or not-for-profit sectors. 


\section{References}

[1] Cash, TF, Fleming, EC, Alindogan, J, Steadman L, Whitehead, A. Beyond body image as a trait: the development and validation of the Body Image States Scale. Eating Disorders: The Journal of Treatment \& Prevention 2002; 10:103-113.

[2] Wiederman, MW. Body image and sexual functioning. In Cash TF, Pruzinsky, T, eds. Body image: A handbook of theory research and clinical practise. New York: Guilford Press, 2002, pp. 287-294.

[3] Woertman, L, Van den Brink, F. Body image and female sexual functioning and behavior: a review. Journal of Sex Research 2012; 49:184-211.

[4] McDonagh, LK, Morrison, TG, McGuire, BE. The naked truth: Development of a scale designed to measure male body image self-consciousness during physical intimacy. The Journal of Men's Studies 2008; 16:253-265.

[5] Dove, NL, Wiederman, MW. Cognitive distraction and women's sexual functioning. Journal of Sex Marital Therapy 2000; 26:67-78

[6] Cash, TF, Maikkula, CL, Yamamiya, Y. "Baring the body in the bedroom": Body image, sexual self-schemas and sexual functioning among college women and men. Electronic Journal of Human Sexuality 2004; 7:http://www.ejhs.org/volume7/bodyimage.html

[7] Lever, J, Frederick, DA, Peplau, LA. Does size matter? Men's and women's views on penis size across the lifespan. Psychology of Men and Masculinity 2006; 7:129-143.

[8] Morrison, TG, Bearden, A, Ellis, SR, Harriman, R. Correlates of genital perceptions among Canadian post-secondary students. Electronic Journal of Human Sexuality 2005; 8:1-22. 
[9] Simpson, P, Adams, J. A structured review and critical analysis of male perceptions of the penis: A comparison between heterosexual men and men who have sex with men (MSM). Men and Masculinities 2017; 1:1-36.

[10] Franzoi, SL, Shields, SA. The Body-Esteem Scale: Multidimensional structure and sex differences in a college population. J Pers Assess 1984; 48:173-178.

[11] Morrison, TG, Morrison, MA, Hopkins, C, Rowan, ET. Muscle mania: Development of a new scale examining the drive for muscularity in Canadian males. Psychology of Men and Masculinity 2004; 5:30-39.

[12] Janda, H, O’Grady, KE. Development of a sex anxiety inventory. J Consult Clin Psychol $1980 ; 48: 169-175$.

[13] Snell, WE, Papini Jr, DR. The Sexuality Scale: An instrument to measure sexual esteem, sexual depression, and sexual preoccupation. The Journal of Sex Research 1989; 26:256-263. [14] Doyle, DM, Engeln, R. Body size moderates the association between gay community identification and body image disturbance. Psychology of Sexual Orientation and Gender Diversity 2004; 1:279-284.

[15] Kaminski, PL, Chapman, BP, Haynes, SD, Own, L. Body image, eating behaviors, and attitudes toward exercise among gay and straight men. Eating Behaviors 2005; 6:179-187. [16] Tiggemann, M, Martins, Y, Kirkbride, A. Oh to be lean and muscular: Body image ideals in gay and heterosexual men. Psychology of Men \& Masculinity 2007; 8:15-24.

[17] Watson, RJ, Adjei, J, Saewyc, E, Homma, Y, Goodenow, C. Trends and disparities in disordered eating among heterosexual and sexual minority adolescents. Int J Eat Disord 2017; $50: 22-31$ 
[18] Blashill, AJ. Elements of male body image: Prediction of depression, eating pathology and social sensitivity among gay men. Body Image 2010; 7:310-316.

[19] Frederick, DA, Essayli, JH. Male body image: The roles of sexual orientation and body mass index across five national US Studies. Psychology of Men \& Masculinity 2016; 17:336351.

[20] Yelland, C, Tiggemann, M. Muscularity and the gay ideal: Body dissatisfaction and disordered eating in homosexual men. Eating behaviors 2003; 4:107-116.

[21] Lacefield, K, Negy, C. Non-erotic cognitive distractions during sexual activity in sexual minority and heterosexual young adults. Arch Sex Behav 2012; 41:391-400.

[22] Bossio, JA, Pukall, CF. Attitude toward one's circumcision status is more important than actual circumcision status for men's body Image and sexual functioning. Arch Sex Behav 2017; 47:771-781.

[23] Gaither, TW, Allen, IE, Osterberg, EC, Alwal, A, Harris, CR, Breyer, BN. Characterization of genital dissatisfaction in a national sample of US men. Arch Sex Behav 2017; 46:2123-2130. [24] Peplau, LA, Frederick, DA, Yee, C, Maisel, N, Lever, J, Ghavami, N. Body image satisfaction in heterosexual, gay, and lesbian adults. Arch Sex Behav 2009; 38:713-725. [25] Šević, S, Ivanković, I, Štulhofer, A. Emotional intimacy among coupled heterosexual and gay/bisexual Croatian men: Assessing the role of minority stress. Arch Sex Behav 2014; 45:1259-1268.

[26] Sandfort, TG, de Keizer, M. Sexual problems in gay men: An overview of empirical research. Annual Review of Sex Research 2001; 12:93-120. 
[27] McDonagh, LK, Morrison, TG, McGuire, BE. Male Body Image Self-Consciousness Scale. In: Fisher, TD, Davis, CM. Yarber, WL, Davis SL eds. Handbook of sexuality-related measures. Thousand Oaks, CA: Sage, 2010, pp 116-117.

[28] McDonagh, LK, Stewart, I, Morrison, MA, Morrison, TG. Development and psychometric evaluation of the Gay Male Sexual Difficulties Scale. Arch Sex Behav 2016; 45:1299-1315.

[29] Basto, M., Pereira, JM. An SPSS R-menu for ordinal factor analysis. Journal of Statistical Software 2012; 46:1-29.

[30] Çokluk, Ö, Koçak, D. Using Horn's parallel analysis method in exploratory factor analysis for determining the number of factors. Educational Sciences: Theory and Practice 2016; 16:537551.

[31] Stevens JP. Applied multivariate statistics for the social sciences (2nd edition). Hillsdale, NJ:Erlbaum, 2009.

[32] Byrne BM. Factor analytic models: Viewing the structure of an assessment instrument from three perspectives. Journal of Personality Assessment 2005; 85:17-32.

[33] Carmines, EG, Zeller, RA. Reliability and Validity Assessment. Sage Publications, Beverly Hills, CA: 1979.

[34] Zumbo BD, Gadermann AM, Zeisser C. Ordinal versions of coefficients alpha and theta for Likert rating scales. Journal of Modern Applied Statistical Methods 2007; 6:21-29

[35] Frederick DA, Essayli JH. Male body image: The roles of sexual orientation and body mass index across five national US Studies. Psychology of Men \& Masculinity 2016; 4:336-351. [36] Sánchez, FJ, Greenberg, ST, Liu, WM, Vilain, E. Reported effects of masculine ideals on gay men. Psychology of Men \& Masculinity 2009; 10:73-87. 
[37] Kvalem, IL, Træen, B, Iantaffi, A. Internet pornography use, body ideals, and sexual selfesteem in Norwegian gay and bisexual men. J Homosex 2016; 63:522-540.

[38] Lanzieri, N, Cook, BJ. Examination of muscularity and body fat depictions in magazines that target heterosexual and gay men. Body Image 2013; 10:251-254.

[39] Tylka, TL. No harm in looking, right? Men's pornography consumption, body image, and well-being. Psychology of Men \& Masculinity 2015; 16:97-107.

[40] Fisher, TD, Moore, ZT, Pittenger, MJ. Sex on the brain?: An examination of frequency of sexual cognitions as a function of gender, erotophilia, and social desirability. Journal of Sex Research 2012; 49:69-77.

[41] Fisher, WA, Byrne, D, White, LA, Kelley, K. Erotophobia-erotophilia as a dimension of personality. Journal of Sex Research 1988; 25:123-151.

[42] Eysenbach, G, Wyatt, J. Using the Internet for surveys and health research. Journal of Medical Internet Research 2002; 4:e13.

[43] Gosling, SD, Vazire, S, Srivastava, S, John, OP. Should we trust web-based studies? A comparative analysis of six preconceptions about internet questionnaires. Am Psychol 2004; 59:93-104.

[44] Laumann, EO, Paik, A, Glasser, DB, Kang, JH, Wang, T, Levinson, B, Moreira Jr, ED, Nicolosi A, Gingell, C. A cross-national study of subjective sexual well-being among older women and men: Findings from the Global Study of Sexual Attitudes and Behaviors. Arch Sex Behav 2006; 35:143-159.

[45] Laumann, EO, Paik, A, Rosen, RC. Sexual dysfunction in the United States: Prevalence and predictors. JAMA 1999; 281:537-544. 
[46] Rowland, DL. Sexual health and problems: Erectile dysfunction, premature ejaculation and male orgasmic disorder. In Grant JE, Potenza MN eds. Textbook of men's mental health. Washington, London: American Psychiatric Publishing 2007, pp. 171-204.

[47] Althof, SE. Quality of life and erectile dysfunction. Urology 2002; 59:803-810.

[48] Loehle, B, McKie, RM, Levere, D, Bossio, JA, Humphreys, TP, Travers, R. Predictors of men's genital self-image across sexual orientation and geographic region. The Canadian Journal of Human Sexuality 2017; 26:130-141. 
Table 1

Factor loadings of M-BISC for gay men items (Sample A, $n=459$ )

\begin{tabular}{|l|l|}
\hline M-BISC Item & Loading \\
\hline $\begin{array}{l}\text { During sex, I would worry that my partner would think my chest is not } \\
\text { muscular enough. }\end{array}$ & .671 \\
\hline $\begin{array}{l}\text { During sexual activity, it would be difficult not to think about how } \\
\text { unattractive my body is. }\end{array}$ & .542 \\
\hline $\begin{array}{l}\text { During sex, I would worry that my partner would think my stomach is } \\
\text { not muscular enough. }\end{array}$ & .805 \\
\hline I would feel anxious receiving a full-body massage from a partner. & .676 \\
\hline $\begin{array}{l}\text { The first time I have sex with a new partner, I would worry that my } \\
\text { partner would get turned off by seeing my body without clothes. }\end{array}$ & .866 \\
\hline $\begin{array}{l}\text { I would feel nervous if a partner were to explore my body before or } \\
\text { after having sex. }\end{array}$ & .813 \\
\hline $\begin{array}{l}\text { During sex, I would prefer to be on the bottom so that my stomach } \\
\text { appears flat. }\end{array}$ & .669 \\
\hline The worst part of having sex is being nude in front of another person. & .872 \\
\hline $\begin{array}{l}\text { I would feel embarrassed about the size of my testicles if a partner } \\
\text { were to see them. }\end{array}$ & .438 \\
\hline $\begin{array}{l}\text { During sexual activity, I would be concerned about how my body } \\
\text { looks to a partner. }\end{array}$ & .845 \\
\hline $\begin{array}{l}\text { If a partner were to put a hand on my buttocks I would think my } \\
\text { partner can feel my fat. }\end{array}$ & .724 \\
\hline $\begin{array}{l}\text { During sexually intimate situations, I would be concerned that my } \\
\text { partner thinks I am too fat. }\end{array}$ & .820 \\
\hline $\begin{array}{l}\text { I could only feel comfortable enough to have sex if it were dark so that } \\
\text { my partner could not clearly see my body. }\end{array}$ & .782 \\
\hline $\begin{array}{l}\text { The idea of having sex without any covers over my body causes me } \\
\text { anxiety. }\end{array}$ & .758 \\
\hline
\end{tabular}




\section{RUNNING HEAD: VALIDATING THE M-BISC WITH GAY MEN}

Table 2

Confirmatory factor analysis models for M-BISC for gay men (Sample B, $n=471$ ).

\begin{tabular}{|c|c|c|c|c|c|c|}
\hline Model & $\chi^{2}(d f)$ & RMSEA $(90 \%$ CI) & CFI & TLI & AIC & $p$ \\
\hline \multicolumn{7}{|l|}{ M-BISC (Gay Men) } \\
\hline 14-items & $\begin{array}{l}446.66 \\
(77)\end{array}$ & $\begin{array}{l}.101 \\
(.092-.011)\end{array}$ & .89 & .87 & 502.66 & $<.001$ \\
\hline Co-vary item $1 \& 3$ & $\begin{array}{l}375.30 \\
(76)\end{array}$ & $\begin{array}{l}.092 \\
(.082-.101)\end{array}$ & .89 & .89 & 433.30 & $<.001$ \\
\hline Co-vary item $4 \& 6$ & $\begin{array}{l}345.54 \\
(75)\end{array}$ & $\begin{array}{l}.088 \\
(.078-.097)\end{array}$ & .92 & .90 & 405.54 & $<.001$ \\
\hline Co-vary item $15 \& 17$ & $\begin{array}{l}298.93 \\
(74)\end{array}$ & $\begin{array}{l}.080 \\
(.071-.090)\end{array}$ & .93 & .92 & 360.93 & $<.001$ \\
\hline Co-vary item $3 \& 14$ & $\begin{array}{l}279.26 \\
(73)\end{array}$ & $\begin{array}{l}.078 \\
(.068-.087)\end{array}$ & .94 & .94 & 343.26 & $<.001$ \\
\hline
\end{tabular}

The Root Mean Square Error of Approximation = RMSEA; Comparative Fit Analysis = CFI; Tucker Lewis Index = TLI; Akaike Information Criterion $=$ AIC. 
RUNNING HEAD: VALIDATING THE M-BISC WITH GAY MEN

Table 3

Factor Loadings for Sample B $(n=471)$

\begin{tabular}{|l|l|}
\hline & $\begin{array}{l}\text { Factor } \\
\text { Loading }\end{array}$ \\
\hline M-BISC Item & .64 \\
\hline $\begin{array}{l}\text { During sex, I would worry that my partner would think my } \\
\text { chest is not muscular enough. }\end{array}$ & .53 \\
\hline $\begin{array}{l}\text { During sexual activity, it would be difficult not to think } \\
\text { about how unattractive my body is. }\end{array}$ & .69 \\
\hline $\begin{array}{l}\text { During sex, I would worry that my partner would think my } \\
\text { stomach is not muscular enough. }\end{array}$ & .60 \\
\hline $\begin{array}{l}\text { I would feel anxious receiving a full-body massage from a } \\
\text { partner. }\end{array}$ & .78 \\
\hline $\begin{array}{l}\text { The first time I have sex with a new partner, I would worry } \\
\text { that my partner would get turned off by seeing my body } \\
\text { without clothes. }\end{array}$ & .74 \\
\hline $\begin{array}{l}\text { I would feel nervous if a partner were to explore my body } \\
\text { before or after having sex. }\end{array}$ & .62 \\
\hline $\begin{array}{l}\text { During sex, I would prefer to be on the bottom so that my } \\
\text { stomach appears flat. }\end{array}$ & .72 \\
\hline $\begin{array}{l}\text { The worst part of having sex is being nude in front of } \\
\text { another person. }\end{array}$ & .46 \\
\hline $\begin{array}{l}\text { I would feel embarrassed about the size of my testicles if a } \\
\text { partner were to see them. }\end{array}$ & .67 \\
\hline $\begin{array}{l}\text { During sexual activity, I would be concerned about how my } \\
\text { body looks to a partner. }\end{array}$ & .77 \\
\hline $\begin{array}{l}\text { If a partner were to put a hand on my buttocks I would think } \\
\text { my partner can feel my fat. }\end{array}$ & $\begin{array}{l}\text { motion } \\
\text { that my partner thinks I am too fat. }\end{array}$ \\
\hline $\begin{array}{l}\text { I could only feel comfortable enough to have sex if it were } \\
\text { dark so that my partner could not clearly see my body. }\end{array}$ \\
\hline $\begin{array}{l}\text { The idea of having sex without any covers over my body } \\
\text { causes me anxiety. }\end{array}$ & .68 \\
\hline
\end{tabular}


Table 4

Endorsement Rates for M-BISC items (Sample A, $n=459$; Sample B, $n=471$ )

\begin{tabular}{|c|c|}
\hline & $\%$ Agreeing \\
\hline \multicolumn{2}{|l|}{ M-BISC Item } \\
\hline $\begin{array}{l}\text { During sex, I would worry that my partner would think my chest } \\
\text { is not muscular enough. }\end{array}$ & $\begin{array}{l}42.9 \% \\
41.4 \% \\
\end{array}$ \\
\hline $\begin{array}{l}\text { During sexual activity, it would be difficult not to think about how } \\
\text { unattractive my body is. }\end{array}$ & $\begin{array}{l}44.9 \% \\
39.0 \% \\
\end{array}$ \\
\hline $\begin{array}{l}\text { During sex, I would worry that my partner would think my } \\
\text { stomach is not muscular enough. }\end{array}$ & $\begin{array}{l}52.1 \% \\
58.0 \% \\
\end{array}$ \\
\hline I would feel anxious receiving a full-body massage from a partner. & $\begin{array}{l}24.4 \% \\
19.8 \%\end{array}$ \\
\hline $\begin{array}{l}\text { The first time I have sex with a new partner, I would worry that } \\
\text { my partner would get turned off by seeing my body without } \\
\text { clothes. }\end{array}$ & $\begin{array}{l}55.1 \% \\
53.1 \%\end{array}$ \\
\hline $\begin{array}{l}\text { I would feel nervous if a partner were to explore my body before } \\
\text { or after having sex. }\end{array}$ & $\begin{array}{l}29.2 \% \\
27.1 \%\end{array}$ \\
\hline $\begin{array}{l}\text { During sex, I would prefer to be on the bottom so that my stomach } \\
\text { appears flat. }\end{array}$ & $\begin{array}{l}28.3 \% \\
26.7 \%\end{array}$ \\
\hline The worst part of having sex is being nude in front of another person. & $\begin{array}{l}20.5 \% \\
17.0 \%\end{array}$ \\
\hline $\begin{array}{l}\text { I would feel embarrassed about the size of my testicles if a partner } \\
\text { were to see them. }\end{array}$ & $\begin{array}{l}6.3 \% \\
6.0 \% \\
\end{array}$ \\
\hline $\begin{array}{l}\text { During sexual activity, I would be concerned about how my body } \\
\text { looks to a partner. }\end{array}$ & $\begin{array}{l}58.0 \% \\
55.2 \%\end{array}$ \\
\hline $\begin{array}{l}\text { If a partner were to put a hand on my buttocks I would think my } \\
\text { partner can feel my fat. }\end{array}$ & $\begin{array}{l}19.2 \% \\
16.7 \% \\
\end{array}$ \\
\hline $\begin{array}{l}\text { During sexually intimate situations, I would be concerned that my } \\
\text { partner thinks I am too fat. }\end{array}$ & $\begin{array}{l}39.6 \% \\
38.6 \% \\
\end{array}$ \\
\hline $\begin{array}{l}\text { I could only feel comfortable enough to have sex if it were dark so that } \\
\text { my partner could not clearly see my body. }\end{array}$ & $\begin{array}{l}16.9 \% \\
14.5 \%\end{array}$ \\
\hline $\begin{array}{l}\text { The idea of having sex without any covers over my body causes me } \\
\text { anxiety. }\end{array}$ & $\begin{array}{l}10.6 \% \\
9.4 \%\end{array}$ \\
\hline
\end{tabular}

Note. Items in bold represent endorsement rates of $25 \%+$. Top proportions are for Sample A; bottom proportions are for Sample B. 